marked in supra clavicular regions. Left side smaller than right side. Percusion: Supra-clavicular flatness bilateral. Dulness everywhere except small area in axillary region on both sides, where a tone of hyper-resonance is obtained. Dulness more marked on left than on right side. Cardiac dulness extends about one inch to left of mammillary line reaching only to left border of sternum. A uscultation: Subcrepitant râles over apices, bilateral. Mucous râles over left lower lobe. Bronchophony marked over apices, increased elsewhere. Broncho-vesicular respiration over upper lobes bilaterally. Fxamination of a scanty amount of sputa on September 29 showed but fow tuberele bacilli. He has taken 100 vapor treatments and gained 10 pounds since June 8.

While there has been marked improvement in the symptoms in every case, some have improved very much more than others. These were a most unfavorable class of patients to treat, being in the advanced stage of the tubercular process with hemorrhages, emaciation, night sweats, anemia and, in fact, scurcely able to breathe at all. In the absence of a specific for tuberculosis, we believe that with proper apparatus and skilful and continued administration much is to be hoped for in this class of patients by the inhalation of antiseptic vapor.

The respiratory movements so limited in tubercular patients are increased; the catarrhal condition of the upper air passages and especially in laryngeal tuberculosis is removed, thereby aiding better introduction of air into the lungs. The pulmonary air-passages are rendered and kept in a more aseptic condition thus minimizing the danger of new invasion. The alimentary tract is undisturbed by strong and irritating drugs, giving ample opportunity for the increase of vitul resistance, by suitable diet and constitutional treatment.

The treatment of this class of patients by the inhalation of antiseptic vapor is both rational and practicable. For when the vapor is properly prepared and administered it is so fine and non-irritating and so intimately mixed with air that it must find its way to every portion of the lung substance that air in any form reaches.

I am fully convinced, from my short experience, that if the proper apparatus is used and the vapor not too strong, and given for from fifteen to twenty minutes twice daily, together with bitter tonics and supportive diet, great relief if not ultimate recovery may be brought to this unfortunate class of sufferers. It has been proved that when the vapor is properly prepared and udministered that it reaches the minutest ramifications of the pulmonary air passages in the healthy lung. This fact being established it is no longer the question; how can medicaments be made to reach the alveoli? But rather, how soon will the therapeutists provide us with a specific for the tubercle bacilli? This done the dread malady of tuberculosis will no longer be credited with one-fourth of our mortality. That so large a number of cases have been relieved of their most distressing symptoms together with physical improvement, inspires a new hope and ambition for more thorough and extensive investigation. Any method of treatment that brings relief to the class of patients that I have treated gives bright promise for those in the incipient stage of the disease.

Orthoform in Tuberculous Laryngitis.-- Neumayer announces that orthoform will relieve the pain which renders swallowing difficult in turberculous laryngitis, buccal ulcerations, cancer of the tongue, etc. The substance can be insufflated or the surface painted with a 10 per cent. solution of the hydrochlorate, renewing the application as often as necessary, orthnform being non-toxic. (Tide Journat, Vol. 29, pages 700 and 1170.)

\section{PULMONARY TUBERCULOSIS WITH SPECIAL REFERENCE TO DIET.}

presented to the Section on Physiology and Dietetics at the Fortyeighth Annual Meeting of the American Medical Association, at Philadelphia, Pa., June 1-4, 1897.

BY HUBBARD WINSLOW MITCHELL, M.D. Member New York Academy of Medicine, Medical Society of the County of New York, New York County Medical dssociation, Phycicians' Mutual Aid Association, Ex-President Medico-Legal Society of New York, Ex.Visiting Surgeon Bellevue Hospital Out-Department.

The purpose of this paper is to set forth some practical observations acquired by direct clinical experience upon the treatment of pulmonary tuberculosis with special reference to the effect exerted upon it by a due application of certain dietary regulations.

THE NATURE OF PUlMONARY TUBERCULOSIS.

Pulmonary tuberculosis is a true inflammatory process set up by a specific morbific influence in the delicate lung tissue and terminating in true ulceration and suppuration of the lung substance. I will briefly recall the anatomy of the lung. The trachea divides into the right and left bronchi. These divide again into secondary and tertiary bronchi, and the subdivision continuing, the bronchial tubes grow more attenuated and more numerous as they subdivide. They also grow more delicate in structure, and when finally they reach a minute size, they are comprised only of a thin membrane lined with pavement epithelium resting upon an elastic fibrous layer. They are then known as the ultimate bronchial tubes. Each one of these terminate in a lozenge shape islet of delicate pulmonary tissue called a pulmonary lobule. Each lobule consists of a vascular membrane in the form of a suc, from the cavity of which are numerous secondary compartments divided by thin partitions projecting from its inner surface. These minute cavities are pulmonary vesicles. Their walls are distensible and elastic, and expand and contract during the respiratory act.

These minute pulmonary vesicles are surrounded by capillary blood vessels which penetrate their purtition walls. The abundant elastic tissue in the walls of these pulmonary vesicles gives to the lung its property of resiliency. These pulmonary vesicles are also called air cells or alveoli, and are largest at the apex of the lung and smallest in the interior. The aggregated mass of the pulmonary vesicles form the spongy or parenchymatous tissue of the lung.

The lung tissue is nourished by the bronchial arteries, which ramify upon the walls of the smallest pulmonary vesicles. The blood is returned through the bronchial veins. The pulmonary vesicles are supplied with lymphatics and nerves, the latter being supplied chiefly by branches from the sympathetic and pneumogastric.

The nature of pulmonary tuberculosis is an inflammatory process called into activity in these delicate structures by the introduction of a special microbe, the tubercle bacillus, which can flourish and multiply only when brought in actual contact with these sensitive and extremely attenuated membranes.

$$
\text { ITS CAUSE. }
$$

When this microbe has succeeded in gaining a lodgment upon the delicate pavement epithelium of a pul. monary vesicle, its specific action at once springs into activity, and this is first a congestion of the capillary vessels of the part, which is speedily followed by a true inflammation. 
Succeeding this is the formation of minute masses which are called tubercle. These tubercle masses are formed in great numbers upon the delicate walls of the vesicles, and in a short time undergo a process called caseation or softening. At the same time they break down the vesicle walls, so that several pulmonary vesicles are thus turned into one.

As this softening process goes on and the matter accumulates in quantity, it is forced into the smaller bronchi, thence passea during the respiratory act into the larger bronchi, and is finally coughed up and expectorated by the patient. The expectorated matters are yellowish or greenish in color, and under a suitable power of the microscope are seen to contain great numbers of pus-cells with bacilli more or less numerous, as well as broken down lung tissue.

It is doubtful if pulmonary tuberculosis is caused in any other way except that mentioned. Heredity plays a very unimportant, if any part at all. Not all persons who inhale bacilli contract this disease. It is only those in whom a special adaptability to harbor the microbe become its victim.

The microbe has a veritable struggle for life. Its journey from the outer world through the air passages to the delicate structure of the vesicle is not without danger to itself, and hence few of them only find a successful lodgment in the pulmonary vesicles, which they must do before they can begin their baleful work. Most of them are arrested and die before they can reach a point favorable for their development. Only the most vigorous life and the fittest are the survivors.

ITS CONTAGIOUS PRINCIPLE.

Pulmonary tuberculosis is contagious when the bacillus is introduced from some source where it has retained its activity and virulence, and when we remember that the sputum from phthisis patients contains great numbers of these bacilli, which are distributed widely through dust and the carelessness with which sputum is voided, it will be seen that the danger from contagion is great, and it is in this way that the bacillus enters the lung by inhalation and the disease is acquired, but contagion by contact with a phthisis patient, and by inhaling his breath is very slight indeed.

\section{ITS SYMPTOMS.}

When the bacillus has invaded the lung tissue the symptoms are quickly manifested. The patient develops a cough which seems first to be of a bronchial type and is marked with expectoration of a mucopurulent character. The early physical signs are those of bronchitis, but very soon dyspnea occurs and becomes more or less severe. Respiration rises from twenty to fifty per minute, and the general distress is usually well marked.

$$
\text { ITS HABITAT. }
$$

The tubercle bacillus can not exert its specific poisonous action unless it finds a congenial habitat, and this is what may be called an alkaline temperament, and this temperament plays a very important part in the acquirement and behavior of phthisis. Persons who are thin, tall and anemic, and those having red or sandy hair, or light blonde hair with a thin pallid skin, pale mucous membranes and weak sexual organs, are those who are very liable to tuberculosia, very much more so, in fact, than do the darker hued or more athletic persons, or those who have the acid temperament. In these alkaline subjects the disease seems to make rapid progress, and.it is in the apices of the lungs, where the pulmonary vesicles are of large size, that the disease seems to locate by preference. In the apex of one or both lungs cavities form more readily, and the disease seems more virulent than when in the middle or lower lobes, and it is these patients who are tall and pale and badly nourished, and whose blood is deficient in red globules who acquire phthisis very readily. The apices are almost always involved, and he resists treatment to a great degree. In these cases also, when the disease has made any progress, the poisonous principle of the disease, whatever it may be (ptomains, or absorbed poison from the tubercle), seems to pervade the entire body, and he has therefore diarrhea, night-sweats, hemorrhages, anorexia, thirst and mal-assimilation of the little food he takes. These patients offer a congenial habitat to the bacilli and fall before their ravages like the morning dew. They are so difficult to treat and so persistent that they seem almost malignant.

When such a weak lung or special temperament, or readiness to receive the disease is found, it becomes a ready prey to the immigrating microbe. In many cases where bacilli are introduced into the lung they are destroyed for some reason, and this reason is either an acid temperament, or an individual power to resist disease, or a failure to gain a favorable lodgment upon the thin and sensitive walls of the air cells.

\section{ITS ECONOMIC VALUE.}

It has been held that disease, and particularly tuberculosis, has a certain economic value in checking the over-population of the earth. In former geologic epochs the exuberance and over-production of animal life has been restrained and held in check by the operation of several influences. The lower orders of animal life that have been so prolific in development have been preyed upon by the higher species of animals who used them as food. Every order of animal life has found a destructive enemy in some other order, and this process of animals preying upon others has served in all geologic ages as a complete check upon the over-production of any one species.

With man, however, the case is different. There is no higher order of animal than himself to hold in check the rate of his increase. To control and repress his too great reproduction, other influences quickly sprang into action. They were three in number. 1, his own exterminating wars; 2, the fearful ravages of disease; 3 , his individual vices.

Man's early tribal quarrels were very destructive and continued in activity until replaced by more fatal methods of modern warfare. These repressing influences acted with such mournful force as to seriously affect, on several occasions, the welfare of mankind. We see in the reign of the Roman Emperor Justinian, A. D. 527-565, that the influence of his wars, to which must be added the famine and disease that followed, destroyed more than one hundred million of human lives and depopulated some of the fairest provinces of the earth. This destruction caused a visible diminution of the human race.

The ravages of disease have also acted as a potent check upon the increase of mankind. As he aggregated into communities and nations and lived in close contiguity with his fellows, he knew nothing of sanitary laws and hence suffered severely from sporadic and epidemic diseases. Plague and famine so baleful 
in their effects were also the result of his ignorance. Tuberculosis played a malignant and destructive part, and it has been stated, destroyed one-third of all those who died of disease. Whether this special disease has any economic value or not we can hardly say, but the question is not without force when we observe closely the character and temperament of its many victims.

The individual vices of man truly have an economic value. Habitual criminals, the cruel and morbidly vicious, the drunkard with his insatiable desire for intoxicants, and the prostitute are all victims of disease, nervous and otherwise, and all lack the mental balance necessary to make them sound and responsible beings. It is from the ranks of these classes that the insane are so largely recruited, and fill our asylums with their mournful presence. When either of these classes are allowed unrestrained action to their vicious or intemperate habits, their career is brought sooner or later to an end, and the prison, the hospital or the grave removes them from the walks of the living world.

ITS OCCURRENCE IN THE LOWER ANIMALS.

In the animal kingdom certain species contract pulmonary tuberculosis more or less readily. The species that acquire this disease are those brought in contact with man, either in the feral or the domestic state. Among the feral group come first the great order of apes, which may be divided into two general elasses, as follows: The cynomorpha or dog apes, and the anthropomorpha or man-like apes.

These apes have been called the catarrhine apes, that is, having a nose with narrow nostrils and a thin septum

Some years ago while visiting West Africa I spent some time on the Congo River and saw considerable numbers of baboons. They are very alert and mischieveous, live in groups of twenty or more, and are fond of the dwellings of man, where their thievish ways cause them to be regarded by the natives as a great nuisance.

On several occasions while we were hunting, a group of baboons would be seen hovering over one of their number who appeared to be unable to move. It was easy to approach, as he was too feeble to escape. Inquiring of the natives I found that the baboons were frequently taken ill with some chest trouble which was similar to that from which the natives themselves suffered. This I learned afterward was phthisis, which is not uncommon among the blacks in the lower Congo districts.

The mandril (cynocephalus mormon) and the magot (macacus sylvanus) are also frequently met with on both banks of the Congo.

In the wild and almost uninhabited country about 150 miles north of Cape Town in South Africa the common baboon is very numerous, and is a most unwelcome visitor to the negroes, who suffer from their thievish and predatory ways. They have little or no fear of man.

An English officer told me the Hottentots and negroes often contracted phthisis on their periodical visits to Cape Town, and it seemed to me that the baboons contracted the disease from the sputum of these natives, which they carelessly voided in their gardens and about their houses. This gentleman had often seen sick baboons presenting the same symptoms as the natives when suffering from phthisis.

One day while hunting in the adjacent hills I saw a baboon lying upon the ground. On my approach he made no attempt to escape, for he was extremely emaciated and had a severe and violent cough. At that time the existence of the tubercle bacillus was not known, but I felt sure that the baboon was suffering from what we now term pulmonary tuberculosis.

THE DOMESTIC GROUP.

The common ox (bos taurus) is so frequently affected with tuberculosis as to require the rigid surveillance of our great abbatoirs by inspectors who are appointed for this special purpose. It is no doubt true that these animals contract the disease from their long and close association with man.

The dog (canis familiaris), and the cat (felis domes. tica) are both very liable to tuberculosis, and this would seem an almost self-evident fact from their intimate association with man.

The duck (anas bosras), the goose (anser anser), and the domestic fowl occasionally contract this disease. It is not improbable that other animals are victims to tuberculosis, but they have no especial interest for us here. We are especially interested in those animals whose flesh and milk we consume as necessary articles of our daily diet.

ITS DIAGNOSIS.

The diagnosis of pulmonary tuberculosis is usually very plain. The presence of cough, expectoration, emaciation, diarrhea, night sweats, loss of appetite, thirst, anorexia with hemorrhages more or less severe, are nearly always present and reveal the true nature of the disease. The unfailing test is, however, the presence of the bacillus in the sputum. Without bacilli the disease is not pulmonary tuberculosis per se. A very early diagnosis can thus be made. The competent and careful physician has little difficulty in arriving at a true diagnosis even without the immediate examination of the sputum. He may begin treatment at once, but must examine the sputum for bacilli in order to confirm his judgment. These examinations should be made frequently during treatment, that he may know if the bacilli are diminishing and whether his patient is really recovering.

ITS PROGNOSIS.

Pulmonary tuberculosis when not modified by treatment is an extremely fatal disease. No accurate percentage of deaths can be given, because these differ with many writers, but once the disease is allowed to run its course without treatment, and especially in one of an alkaline temperament and a generally anemic condition, it is a rapid and terribly fatal disease.

$$
\text { TREATMENT. }
$$

We are called upon to treat a very complex disease. At the very outset we must not forget that pulmonary tuberculosis is an inflammatory disease of the spongy tissue of the lung, due to a special microbe and followed by a true ulcerative and suppurative process in the delicate lung tissue. It may be described briefly as a special ulceration in the pulmonary vesicles with an expectoration of the suppurating matters, and any treatment which is destined to cure or even relieve it, must be addressed to this ulcerating condition of the lung.

To successfully treat a disease so lethal in character and so complex in nature, it would seem that some remedy which can be introduced into the body at short intervals and for a long period of time, something that will act as an antiseptic by saturating the blood and modifying or destroying the bacillus and at 
the same time inflict no injury upon the organs of the patient, would appear to be an ideal remedy.

A considerable percentage of cases of phthisis belong to the alkaline temperament, and a remedy having an acid reaction would appear to be especially indicated. From experience, which has been considerable, I believe that a solution of the halogen group of salts, with the hypochlorite of sodium added in due proportion, is the best remedy to modify and perhaps cure pulmonary tuberculosis.

This remedy acidifies the blood when saturated with it, and almost immediately relieves the extreme cachexia, loss of appetite, weakness and night sweats which form such distressing symptoms. The cough which is nearly always present, sometimes distressing and even terrible, can easily be relieved by giving a mixture of iodid of potassium (10 grains) with a little sulphate of morphin ( $\frac{1}{5}$ grain) and a syrup as a vehicle, or a capsule of quinin grs. iij. (.2) and pulvis opii gr. ss. (.03) may be given during the day and at bedtime.

For the hectic fover nothing is better than a capsule containing grams 26 quinin, and grams .0014 sulphate of strychnin once or twice daily.

Alcohol in the form of whisky or brandy is nearly always indicated, especially when the disease has made any progress, and when the vital powers are feeble and the pulse weak and rapid, I usually give 30 c.c. of whisky slightly diluted with plain or mineral water twice or thrice daily for perhaps a month at a time, and then omit it for a while according to the progress of the case. It can be resumed at any time subsequently. Wine and malt liquors should never be given, as they are apt to disagree with the stomach.

\section{DIET.}

Proper diet forms an essential part of the treatment of phthisis. When we are dealing with a severe and wasting disease the diet should receive especial attention. The physician must always prescribe such articles as are nutritious and easily assimilated. Meats of all kinds, fish, shell-fish and eggs may always be given. Rich soups of beef, mutton or chicken are especially valuable, and are palatable and nutritious. Puddings of the farinaceous kind with good bread and butter are also nutritious and well borne. Coffee with cream, strong tea, chocolate, milk and milk punch, may be given freely as beverages. Cooked fruits may be given cautiously, but never raw fruits, as they are apt to induce a troublesome diarrhea. High seasoning with salt, pepper, mustard and vinegar and other condiments are well borne and act as stimulants and assimilants to the digestive organs, and usually are agreeable to the patient.

I can not speak too strongly upon the inestimable value of cold water as a beverage in phthisis. We must remember that the blood is deprived of its watery parts to a large extent by the wasting action of the disease, and hence the thirst which is sometimes very great, and the hot and burning skin so often present. I always insist upon the patient drinking large quantities of cold water at any time without limit. He may drink ordinary potable water or use one of the many excellent mineral waters now so easily obtainable. Among those I like best are Vichy, Seltzer, Appollonaris, Poland Spring and the Great Bear Spring. All of these are most excellent waters, and when iced are palatable to the patient.

The daily warm bath is of great value in reducing the surface temperature. It can be taken any time during the twenty-four hours. The temperature of the bath can safely vary from 90 to $100 \mathrm{Fuhr}$, or even higher if agreeable to the patient.

\section{REST AND SLEEP.}

Perhaps second in importance only to water, is rest and sleep. Phthisis is a wasting disease and the muscular power of the patient is largely lost through atrophy of muscular tissue, and any effort that is not absolutely needed is harmful. Let no restriction be placed upón his hours of rest and sleep.

In conclusion let it be remembered that a drug of an acid reaction is the one specially required, and that a wisely selected and generous diet, together with liberal potations of cold water, the bath and sleep, when prescribed by the wise physician, form the best means at our command to combat, relieve and cure the dreaded disease known as pulmonary tuberculosis. 747 Madison Ave.

\section{UN THE DIET AND GENERAL CARE OF CONSUMPTIVES COMING TO SOUTH. ERN CALIFORNIA.}

Presented to the Section on Phisiology and Dietetics at the Fortyeighth Annual Meeting of the American Medical Association. at Philadelnhia, Pa.; June 1-4, 1897. BY GEORGE L. COLE, M.D. LOS ANGELES, CAL.

When asked to contribute to this Section I recalled the fact that only a few days previously a patient consulted me who bad recently been sent to this region by his physician in one of the Middle Eastern States. His doctor had told him to go to Southern California, find a place suitable to live in, receive the benefit of the climate and not waste his money on either physicians or drugs, to use his own judgment and when he thought best to return to the Eust. Not this case alone, but the many similar cases, impressed me with the fact that a few words along this line may result in benefit to some who may seek such a change in the future.

Imagine the responsibility thus laid upon the patient. How shall he find the place suitable for himself? How should he know where to find suitable lodgings and table? How shall he learn of the proper clothing to wear in a climate wholly different from that he has left? Most of all, how is he to judge competently of the improvement made at the end of three, six or twelve months, in order that he may know whether best to remain longer or return to his home? Because he finds himself transported from snow and ice to a scene in which sunshine and flowers abound, he immediately dons his summer clothing and succeeds in contracting a cold, if nothing worse. He takes his first day's outing in an orange grove and proceeds to demoralize his digestive apparatus by partaking of the golden fruit, unripe and unfit to eat. He returns to his temporary quarters at his hotel, to awaken the next morning in anything but an amiable mood in which to set out in search of a permanent location. His stomach upset, snuffling with a cord, he finds some pleasant rooms situated on the north side of a building. He does not notice the absence of the sun's rays from morning till night, but rather has his attention called to the "beautiful mountain view" by his would-be landlord, who is quietly reserving his sunny rooms for others more experienced in the requirements of the invalid. The patient does not notice that his room has no 